\title{
Comparison of laparotomic omentopexy vs. laparoscopic abomasopexy treatments of left displaced abomasum in dairy cows under field conditions: biochemical analysis
}

\author{
Tomáš Haloun ${ }^{1}$, Radko Rajmon ${ }^{1}$, Dalibor Řehák ${ }^{2}$, Helena Hartlová1, Zuzana Ptáčková1, \\ Jaroslav Marek ${ }^{3}$, Petra Folková ${ }^{2}$, Petr Slavík ${ }^{1}$, Jan Sterc ${ }^{4}$ \\ ${ }^{1}$ Czech University of Life Sciences Prague, Faculty of Agrobiology, Food and Natural Resources, \\ Department of Veterinary Sciences, Prague, Czech Republic \\ ${ }^{2}$ Institute of Animal Science, Department of Biometric Unit, Prague-Uhř́něves, Czech Republic \\ ${ }^{3}$ University of Pardubice, Department of Mathematics and Physics, Pardubice, Czech Republic \\ ${ }^{4}$ ORTHOVET s.r.o., private veterinary practice, Moravany, Czech Republic \\ Received March 31, 2020 \\ Accepted June 22, 2020
}

\begin{abstract}
The objective of this retrospective study was to compare the effects of the two methods (laparoscopic or laparotomic) of LDA (left displaced abomasum) correction under field conditions by means of survival rate and biochemical profile evaluation. Holstein cows from one farm with LDA over a 20-month period were included in the study. Cows underwent laparoscopic abomasopexy (Janowitz's method, LS) or a laparotomic right flank omentopexy (Dirksen's method, LT). Blood samples for biochemical analysis were taken just prior to surgery (D1) and on days 10 (D10) and 30 (D30) following surgery. Blood profiles of healthy cows identified from the farm's routine transition cow monitoring program were used as control (C). Aiming to minimize disruptive effects of quite a long period of data collection, the cows' biochemical profile was evaluated in three orthogonal comparisons: LS cows vs. control group, LT cows vs. control group, and LS cows vs. LT cows. The rate of animal survival was similar for both methods (loss of about $11 \%$ until 30 days after treatment). Most of the blood parameters from LS and LT groups were comparable in all three sampling terms indicating continual organism recovery. At D10 the difference of higher cholesterol concentration and lower haptoglobin concentration were favourable for the LS group $(P<0.05)$. Total protein, calcium, magnesium and albumin showed more positive dynamics in the LS group too. This proves previous laboratory and clinical indices of expediency of LDA laparoscopy treatment under field conditions.
\end{abstract}

Abomasal displacement, LDA, cattle, laparotomy, laparoscopy, recovery, surgery

Left displaced abomasum (LDA) is considered as an important production disease of high producing dairy cows primarily related to the periparturient period, a challenging time when cows undergo changes in their metabolism and are more susceptible to diseases (Markusfeld 1986; Pistkova et al. 2019). Reported prevalence of LDA is approximately $2 \%$ on well-managed farms (Sickinger 2017).

Left displaced abomasum disrupts the passage of digesta with continuing excretion of hydrochloric acid. This scenario has a negative impact on acid-base and ion balance, dehydration, and the total nutritional balance of cow. Affected animals can suffer from hypokalaemia, hyponatraemia and hypochloraemia together with metabolic alkalosis. Dehydration and haemoconcentration are identified. At the same time catabolic processes occur manifested by high blood urea concentration as a final product of protein catabolism, as well as by hypoproteinaemia and hypoalbuminaemia which sometimes reflect protein synthesis depression too (Delgado-Lecaroz et al. 2000; Constable et al. 2013). Indices of liver dysfunction as well as of negative energy balance (NEB) are documented in affected cows (Whitaker 2004). An increase of haptoglobin in cows with LDA indicates inflammation processes (Simões et al. 2017). Contemporarily, NEB, namely higher beta

Address for correspondence:

MVDr. Jan Šterc, PhD.

ORTHOVET s.r.o.

E-mail:stercj@seznam.cz

Moravany, Czech Republic

http://actavet.vfu.cz/ 
hydroxybutyrate (BHB) concentration, is considered as an important predisposing factor of LDA (LeBlanc et al. 2005). Another predisposing factor is hypocalcaemia (Neves et al. 2018).

Surgery is a well-documented mode of LDA correction (Niehaus 2016). Right flank laparotomic omentopexy (Dirksen 1967) is a commonly used method. A disadvantage of the method is substantial invasion into the organism. Laparoscopic methods are generally less invasive and less painful (Newman 2009). Among them, ventral abomasopexy according to Janowitz (1998) is the most common approach of laparoscopic LDA correction under field conditions.

Limited numbers of studies compared the effectiveness of laparoscopic ventral abomasopexy with laparotomic right flank omentopexy according to Dirksen. Wittek et al. (2009) mentioned improved recovery of rumen and abomasum motility and quicker return of milk production, although these results were only numerically but not significantly different. In a study focused on indicators of peritoneal inflammation, laparoscopy was evaluated as a favourable method (Wittek et al. 2012). In a university clinical study, See ger et al. (2006) found significant differences in normalization of bilirubin concentration and glutamate dehydrogenase (GDH) activity which were more favourable for animals after laparoscopic surgery. In contrast, Roy et al. (2008) did not find any significant differences in all parameters monitored in their field study.

The aim of the study was to verify by assessment of biochemical profile whether laparoscopic abomasopexy and laparotomic omentopexy procedures for LDA correction had similar recovery success for cows under field conditions.

\section{Materials and Methods}

The study was performed as a retrospective data analysis of herd and veterinary records from a farm of 1000 high-producing Holstein cows with an average of $11,500 \mathrm{~kg}$ milk production. Processed data come from the period of 20 months during which both methods of LDA surgery - laparotomic omentopexy (LT; Dirksen 1967) and ventral laparoscopic abomasopexy (LS; Janowitz 1998) - were performed.

\section{Animals}

Cows indicated for LDA surgery with no other intercurrent disease were randomly assigned to the LT or LS group. Nine cows ranging from first to fourth lactation were subjected to LT. The LDA was diagnosed on day 1 to day 22 after parturition. The LS method was used in 44 cows ranging from first to sixth lactations. The LDA was diagnosed on day 4 to day 48 after parturition. Blood samples for biochemical analyses were taken on the day of surgery (D1) and day 10 (D10) and 30 (D30) after surgery to monitor recovery. A group of 26 cows that were closest to the age and days in milk (DIM) of the experimental cows and assessed as not having LDA or any other major health concern, were selected as controls $(C)$ and their data from the herd's transition cow monitoring program were used.

\section{Biochemical analysis}

Biochemical parameters of harvested serum were used for this study. Fluid colorimetry (analyser Erba Lachema XL200) with the use of commercial kits (Erba Lachema, s.r.o., Brno, Czech Republic) were used for analysis non-esterified fatty acids (NEFA), triacylglycerols (TAG), cholesterol (CHOL), total protein (TP), albumin (ALB), urea (UREA), gamma-glutamyl transferase (GGT), aspartate aminotransferase (AST), alkaline phosphatase (ALP), phosphorus (P), calcium (Ca) and magnesium (Mg). Electrolytes, sodium (Na), potassium $(\mathrm{K})$ and chloride $(\mathrm{Cl})$, were analysed by ionic selective electrodes on the same analyser. Haptoglobin (HAPT) was analysed by commercial kit (Haptoglobin Bovine, Tridelta Development, Ireland), beta-hydroxybutyrate (BHB) was analysed by commercial kit (RANDOX NEFA, RANDOX RANBUT, Laboratories Ltd., UK) and glucose (GLU) was analysed by commercial kit (GLUL 500 S, PLIVA - Lachema diagnostika s.r.o., Brno, Czech Republic).

Data by Pechova et al. (2009) were used as reference limits for individual biochemical parameters.

\section{Statistical analysis}

For basic surgical outcome analysis chi-squared test was used with a $P$ value $<0.05$.

Because of the relatively long period of data collecting (20 months), biochemical parameters were evaluated under three partial comparisons, always comparing animals of the same period of sample collection: laparoscopy operated cows vs. control group $(\mathrm{LS} \times \mathrm{C})$, laparotomy operated cows vs. control group $(\mathrm{LT} \times \mathrm{C})$ and laparoscopy 
operated cows vs. laparotomy operated cows $(\mathrm{LS} \times \mathrm{LT})$. Thirty-seven animals were included in $\mathrm{LS} \times \mathrm{C}$ analysis $(\mathrm{LS}-12, \mathrm{C}-25)$. Thirteen animals were included in $\mathrm{LT} \times \mathrm{C}$ analysis $(\mathrm{LT}-5, \mathrm{C}-8)$. Seventeen animals were included in the LS $\times$ LT analysis (LS $-11, \mathrm{LT}-6)$.

Data underwent exploratory data analysis focusing on detecting outliers and verifying the normality of distribution of all dependent variables. The data that were not normally distributed (NEFA, BHB, TAG, CHOL, UREA, GGT, AST, ALP, K, P, HAPT) were transformed by natural logarithms. Data were evaluated by mixed linear model with repeated measures procedure MIXED (version 9.3; SAS Institute Inc., Cary, NC). Parameters were estimated by the REML method. The model was structured to determine the effect of period and the combined effect of group (LS, LT, C) and day after surgery. Due to repeated measures within each cow, random (co)variances between days after surgery were summarized by residual R matrix. As alternatives, the compound symmetry, heterogeneous compound-symmetry, unstructured, autoregressive of order 1 and the Toeplitz covariance structures were compared. The compound-symmetry (GLU, NEFA, TAG, CHOL, TP, ALB, UREA, GGT, Cl, P, Ca) and heterogeneous compound-symmetry (Na, K, Mg, BHBlog, ASTlog, ALPlog, HAPTlog) structures were found to be the most appropriate in accordance with Akaike's Information Criterion and the Schwartz Bayesian Criterion (Littell et al. 2000). The least square means were calculated, and multiple comparisons were made in simple-effect slices, with $P$ values adjusted using Tukey's procedure. The least squares method (LSM) of transformed variables and their confident limits $(\alpha=0.05)$ were retransformed to the original scale.

\section{Results}

In the LS group 5 cows died within 30 days after surgery, 5 animals were culled before finishing the 305-d lactation and 37 cows finished the 305-d lactation. One LT cow died, and 8 cows finished the $305-d$ lactation. There was no significant difference in these losses in terms of surgical procedure.

Results of serum biochemical analyses of cows that underwent laparoscopy (LS group) and results of a related control group are shown in Table 1. Results of serum biochemical analyses of cows that underwent laparotomy (LT group) compared to the control group are shown in Table 2. Comparisons of serum parameter values between LS and LT groups are shown in Table 3. Parameters without any significance (effect of group or time course) in a particular analysis are not shown.

\section{Discussion}

The rate of basic surgical intervention outcome was similar for both of the methods verified. The loss of about $11 \%$ is also comparable to published papers (Seeger et al. 2006; Roy et al. 2008).

The biochemical profile indicates metabolic changes typical of LDA but also a metabolic overload typical of the transition period: On D1, evidence of NEB in conjunction with lipomobilization was obvious both for LT and LS cows with NEFA and BHB concentrations elevated above limits $(>0.35 \mathrm{mmol} / \mathrm{l}$ and $>1.0 \mathrm{mmol} / \mathrm{l}$, respectively) and low CHOL concentration (limits 2.6-5.2 mmol/l). Cows with BHB concentrations higher than $1.0 \mathrm{mmol} / \mathrm{l}$ are at higher risk of health issues or decreased milk productivity (Whitaker 2004). Evaluation of LS and C cows shows also a significant increase of TAG in diseased cows (limits $0.17-0.51 \mathrm{mmol} / \mathrm{l}$ ). This one-off finding is probably related to higher NEFA values of diseased animals from this selected dataset $(\mathrm{LSM}=1.15 \mathrm{mmol} / \mathrm{l})$, as TAG are synthesized in the liver from circulated NEFA (Illek et al. 2011).

These biochemical changes are considered not only as a consequence of LDA but also as a risk factor for LDA in high producing cows after calving (Van Winden and Kuiper 2003; LeBlanc et al. 2005). Concentrations of NEFA, BHB and CHOL indicated that C cows also underwent NEB, although not as severe as LDA cows. For this reason, on D30 (i.e., one month from the operation plus an additional month from calving) blood serum values returned to normal ones not only at LDA groups but at $\mathrm{C}$ groups as well. However, the mean values of BHB on D30 are generally close to the upper limit, which reflects ongoing NEB in many cows at this period. Because these cows were 30-70 DIM, we consider this as a normal situation (Whitaker 2004; Pechova et al. 2009). 
Table 1A. Biochemical profile of cows operated using laparoscopy vs. control.

\begin{tabular}{lccccc}
\hline \multirow{2}{*}{ Indicator (mmol/1) } & \multirow{2}{*}{ Day } & \multicolumn{2}{c}{ Laparoscopy } & \multicolumn{2}{c}{ Control } \\
\cline { 3 - 6 } & 1 & $127.53^{1}$ & SE & Mean & SE \\
\hline \multirow{2}{*}{$\mathrm{Na}$} & 30 & $119.82^{1}$ & 2.95 & 125.02 & 1.37 \\
& 1 & $2.05^{\mathrm{a}}$ & 0.07 & 121.18 & 2.19 \\
$\mathrm{Ca}$ & 30 & 2.20 & 0.08 & $2.25^{\mathrm{a}}$ & 0.05 \\
& & & 2.39 & 0.0 \\
\hline
\end{tabular}

a - mean values with the same superscript within the row differ significantly $(P<0.05)$

1 - mean values of the indicator with the same superscript within the column differ significantly $(P<0.05)$

$\mathrm{Na}$ - sodium; $\mathrm{Ca}$ - calcium

Table 1B. Biochemical profile of cows operated using laparoscopy vs. control.

\begin{tabular}{|c|c|c|c|c|c|c|c|}
\hline \multirow{2}{*}{ Indicator } & \multirow{2}{*}{ Day } & \multicolumn{3}{|c|}{ Laparoscopy } & \multicolumn{3}{|c|}{ Control } \\
\hline & & Mean_N & Lower_95 & Upper_95 & Mean_N & Lower_95 & Upper_95 \\
\hline \multirow{2}{*}{ NEFA (mmol/1) } & 1 & $1.15^{\mathrm{A}, \mathrm{I}}$ & 0.74 & 1.77 & $0.36^{\mathrm{A}, \mathrm{I}}$ & 0.26 & 0.49 \\
\hline & 30 & $0.12^{\mathrm{I}}$ & 0.07 & 0.18 & $0.10^{\mathrm{I}}$ & 0.07 & 0.15 \\
\hline \multirow{2}{*}{ BHB (mmol/l) } & 1 & $2.14^{\mathrm{A}, \mathrm{I}}$ & 1.39 & 3.28 & $0.62^{\mathrm{A}}$ & 0.46 & 0.84 \\
\hline & 30 & $0.63^{\mathrm{I}}$ & 0.47 & 0.84 & 0.69 & 0.55 & 0.87 \\
\hline \multirow{2}{*}{ TAG (mmol/l) } & 1 & $0.17^{\mathrm{A}, \mathrm{I}}$ & 0.15 & 0.18 & $0.12^{\mathrm{A}}$ & 0.11 & 0.13 \\
\hline & 30 & $0.11^{\mathrm{I}}$ & 0.10 & 0.13 & 0.13 & 0.12 & 0.14 \\
\hline \multirow{2}{*}{ CHOL (mmol/1) } & 1 & $1.63^{\mathrm{A}, \mathrm{I}}$ & 1.26 & 2.10 & $2.50^{\mathrm{A}, \mathrm{I}}$ & 2.07 & 3.01 \\
\hline & 30 & $3.55^{\mathrm{I}}$ & 2.73 & 4.62 & $4.14^{\mathrm{I}}$ & 3.39 & 5.06 \\
\hline \multirow{2}{*}{$\operatorname{AST}(\mu \mathrm{kat} / \mathrm{l})$} & 1 & $2.72^{\mathrm{A}, \mathrm{I}}$ & 2.13 & 3.46 & $1.45^{\mathrm{A}, 1}$ & 1.22 & 1.73 \\
\hline & 30 & $1.05^{\mathrm{I}}$ & 0.87 & 1.26 & $1.15^{1}$ & 0.99 & 1.33 \\
\hline \multirow{2}{*}{ HAPT(g/l) } & 1 & $1.20^{\mathrm{A}, \mathrm{I}}$ & 0.88 & 1.62 & $0.55^{\mathrm{A}}$ & 0.44 & 0.68 \\
\hline & 30 & $0.49^{\mathrm{I}}$ & 0.29 & 0.81 & 0.57 & 0.39 & 0.83 \\
\hline
\end{tabular}

A - mean values with the same superscript within the row differ significantly $(P<0.01)$

1 - mean values of the indicator with the same superscript within the column differ significantly $(P<0.05)$

I - mean values of the indicator with the same superscript within the column differ significantly $(P<0.01)$

NEFA - non-esterified fatty acids; BHB - beta-hydroxybutyrate; TAG - triacylglycerols; CHOL - cholesterol; AST - aspartate aminotransferase; HAPT - haptoglobin

The lipomobilization effect and starvation in dairy cows are associated with a higher load and decrease of synthetic activity of the liver parenchyma (Staufenbiel et al. 2007). This was reflected by high AST activity or by low values of TP, ALB and UREA. Comparison of LS and LT groups (Table 3) on D10 showed that there is a certain delay of negative effect of LDA on UREA concentrations in both groups and also on the ALB value (this for the LT group only).

Hypocalcaemia as an important predisposing factor is often diagnosed in cows with LDA (Neves et al. 2018). Our dataset indicates that both cows with LDA and cows in the control group suffered from subclinical hypocalcaemia (Ca limits: 1.6-2.25 mmol/1). After surgical correction $\mathrm{Ca}$ concentrations returned to normal values.

Lower than normal concentrations were also observed for other ions, namely $\mathrm{Na}, \mathrm{Cl}, \mathrm{K}$ and $\mathrm{Mg}$ while comparable values were found in the LDA groups and the control group. Occasional significant changes in time ( $\mathrm{Mg}$ increase or Na decrease) were not related to LDA. Hypokalaemia was found only in the LT group in the LT $\times \mathrm{C}$ analysis. Electrolytes $\mathrm{Na}, \mathrm{K}$, and $\mathrm{Cl}$ are considered as indicators of disease severity. Higher concentrations of $\mathrm{Na}$ and $\mathrm{K}$ are presented in animals with doubtful or poor prognosis. Hypokalaemia is considered as a consequence of retaining $\mathrm{K}$ in the digestive system (Rohn et al. 2004). 
Table 2A. Biochemical profile of cows operated using laparotomy vs. control.

\begin{tabular}{lccccc}
\hline \multirow{2}{*}{ Indicator } & Day & \multicolumn{2}{c}{ Laparotomy } & \multicolumn{2}{c}{ Control } \\
\cline { 3 - 6 } & 1 & $64.15^{1}$ & SE & Mean & SE \\
\hline \multirow{2}{*}{$\mathrm{TP}(\mathrm{g} / \mathrm{l})$} & 30 & $79.40^{1}$ & 5.11 & $61.46^{1}$ & 3.61 \\
& 1 & $3.79^{\mathrm{A}, 1}$ & 5.11 & $70.45^{1}$ & 3.61 \\
$\mathrm{~K}(\mathrm{mmol} / \mathrm{l})$ & 30 & $5.50^{1}$ & 0.27 & $4.95^{\mathrm{A}}$ & 0.16 \\
& & & 0.72 & 5.59 & 0.51 \\
\hline
\end{tabular}

A - mean values with the same superscript within the row differ significantly $(P<0.01)$

1 - mean values of the indicator with the same superscript within the column differ significantly $(P<0.05)$

$\mathrm{TP}$ - total protein; $\mathrm{K}$ - potassium

Table 2B. Biochemical profile of cows operated using laparotomy vs. control.

\begin{tabular}{|c|c|c|c|c|c|c|c|}
\hline \multirow{2}{*}{ Indicator } & \multirow{2}{*}{ Day } & \multicolumn{3}{|c|}{ Laparotomy } & \multicolumn{3}{|c|}{ Control } \\
\hline & & Mean_N & Lower_95 & Upper_95 & Mean_N & Lower_95 & Upper_95 \\
\hline \multirow{2}{*}{ NEFA (mmol/1) } & 1 & $0.67^{\mathrm{a}}$ & 0.28 & 1.63 & $0.21^{\mathrm{a}}$ & 0.11 & 0.39 \\
\hline & 30 & 0.22 & 0.09 & 0.54 & 0.31 & 0.17 & 0.59 \\
\hline \multirow{2}{*}{$\mathrm{BHB}(\mathrm{mmol} / \mathrm{l})$} & 1 & $1.70^{\mathrm{I}}$ & 0.69 & 4.16 & 0.72 & 0.38 & 1.35 \\
\hline & 30 & $0.49^{\mathrm{I}}$ & 0.23 & 1.06 & 0.74 & 0.43 & 1.27 \\
\hline \multirow[b]{2}{*}{$\mathrm{CHOL}(\mathrm{mmol} / \mathrm{l})$} & 1 & $1.51^{\mathrm{a}, \mathrm{I}}$ & 1.04 & 2.21 & $2.69^{\mathrm{a}, \mathrm{I}}$ & 2.06 & 3.51 \\
\hline & 30 & $3.98^{\mathrm{I}}$ & 2.73 & 5.80 & $4.65^{\mathrm{I}}$ & 3.56 & 6.07 \\
\hline \multirow{2}{*}{ UREA (mmol/1) } & 1 & 2.77 & 2.05 & 3.76 & $2.75^{\mathrm{I}}$ & 2.22 & 3.41 \\
\hline & 30 & $3.18^{\mathrm{a}}$ & 2.35 & 4.31 & $5.02^{\mathrm{a}, \mathrm{I}}$ & 4.05 & 6.23 \\
\hline \multirow{2}{*}{ GGT ( $\mu \mathrm{kat} / \mathrm{l})$} & 1 & $0.27^{1}$ & 0.18 & 0.40 & 0.28 & 0.21 & 0.37 \\
\hline & 30 & $0.39^{1}$ & 0.27 & 0.58 & 0.32 & 0.25 & 0.43 \\
\hline \multirow{2}{*}{ HAPT (g/l) } & 1 & $1.15^{\mathrm{A}, \mathrm{I}}$ & 0.65 & 2.02 & $0.32^{\mathrm{A}}$ & 0.23 & 0.45 \\
\hline & 30 & $0.37^{\mathrm{I}}$ & 0.18 & 0.75 & 0.30 & 0.18 & 0.50 \\
\hline
\end{tabular}

a - mean values with the same superscript within the row differ significantly $(P<0.05)$

A - mean values with the same superscript within the row differ significantly $(P<0.01)$

1 - mean values of the indicator with the same superscript within the column differ significantly $(P<0.05)$

I - mean values of the indicator with the same superscript within the column differ significantly $(P<0.01)$

A common finding in LDA groups was a highly significant increase of HAPT on D1 in comparison to the control group and its decrease in time. Haptoglobin is one of the acute phase proteins considered as an important indicator of inflammation in the organism (Simões et al. 2017).

Direct comparison of animals treated with the LS method as opposed to LT revealed that most of the blood indices in the LS and LT groups were comparable at all three sampling terms, but on D10 the differences of higher CHOL and lower HAPT concentrations were favourable for the LS group. There was also a quicker normalization of other parameters in the LS group. The total protein, $\mathrm{Ca}, \mathrm{Mg}$ and $\mathrm{ALB}$ even showed a significant decrease on D10 in the LT group (but not in the LS group). These findings agree with Wittek et al. (2009), who documented a more rapid normalization of abomasum and rumen motility after laparoscopy or with the Wittek et al. (2012), where the same team - based on indicators of peritoneal inflammation - evaluated laparoscopy as probably less stressful and more favourable method. Also, Seeger et al. (2006) found significant differences in normalization of bilirubin level and activity of GDH favourable for animals with laparoscopic surgery. Nevertheless, all these studies were conducted under clinical or even 
Table 3A. Biochemical profile of cows operated using laparoscopy vs. cows operated using laparotomy.

\begin{tabular}{|c|c|c|c|c|c|}
\hline \multirow{2}{*}{ Indicator } & \multirow{2}{*}{ Day } & \multicolumn{2}{|c|}{ Laparoscopy } & \multicolumn{2}{|c|}{ Laparotomy } \\
\hline & & Mean & $\mathrm{SE}$ & Mean & $\mathrm{SE}$ \\
\hline \multirow{3}{*}{$\mathrm{TP}(\mathrm{g} / \mathrm{l})$} & 1 & $63.80^{1, I}$ & 3.61 & 68.00 & 4.71 \\
\hline & 10 & $74.84^{2}$ & 3.61 & 67.50 & 4.75 \\
\hline & 30 & $80.35^{\text {II }}$ & 3.68 & 73.88 & 4.97 \\
\hline \multirow{3}{*}{ ALB (g/l) } & 1 & 27.69 & 1.33 & $29.62^{1}$ & 1.73 \\
\hline & 10 & 27.28 & 1.33 & $23.92^{2}$ & 1.73 \\
\hline & 30 & 28.48 & 1.35 & 26.61 & 1.83 \\
\hline \multirow{3}{*}{$\mathrm{Ca}(\mathrm{mmol} / \mathrm{l})$} & 1 & $2.02^{1}$ & 0.07 & 2.15 & 0.09 \\
\hline & 10 & $2.21^{2}$ & 0.07 & 2.20 & 0.09 \\
\hline & 30 & 2.20 & 0.07 & 2.24 & 0.10 \\
\hline \multirow{3}{*}{$\mathrm{Mg}(\mathrm{mmol} / \mathrm{l})$} & 1 & $0.67^{1, \mathrm{I}}$ & 0.08 & $0.65^{1}$ & 0.09 \\
\hline & 10 & $0.96^{2}$ & 0.12 & 0.83 & 0.15 \\
\hline & 30 & $1.24 \mathrm{II}$ & 0.15 & $1.25^{2}$ & 0.22 \\
\hline
\end{tabular}

1,2 - mean values of the indicator with different superscripts within the column differ significantly $(P<0.05)$

I,II - mean values of the indicator with different superscripts within the column differ significantly $(P<0.01)$

$\mathrm{TP}$ - total protein; ALB - albumin; $\mathrm{Ca}$ - calcium; $\mathrm{Mg}$ - magnesium

Table 3B. Biochemical profile of cows operated using laparoscopy vs. cows operated using laparotomy.

\begin{tabular}{|c|c|c|c|c|c|c|c|}
\hline \multirow{2}{*}{ Indicator } & \multirow{2}{*}{ Day } & \multicolumn{3}{|c|}{ Laparoscopy } & \multicolumn{3}{|c|}{ Laparotomy } \\
\hline & & Mean_N & Lower_95 & Upper_95 & Mean_N & Lower_95 & Upper_95 \\
\hline \multirow{3}{*}{ NEFA (mmol/l) } & 1 & $0.8^{\mathrm{I}, 1}$ & 0.49 & 1.32 & $0.66^{1}$ & 0.34 & 1.25 \\
\hline & 10 & $0.2^{\mathrm{II}}$ & 0.12 & 0.33 & 0.25 & 0.13 & 0.48 \\
\hline & 30 & $0.26^{2}$ & 0.16 & 0.42 & $0.15^{2}$ & 0.08 & 0.31 \\
\hline \multirow{3}{*}{ BHB (mmol/1) } & 1 & $1.83^{\mathrm{I}, 1}$ & 0.94 & 3.54 & $1.55^{1}$ & 0.64 & 3.74 \\
\hline & 10 & $0.41^{\mathrm{II}}$ & 0.25 & 0.68 & $0.44^{2}$ & 0.23 & 0.87 \\
\hline & 30 & $0.62^{2}$ & 0.39 & 0.99 & 0.65 & 0.35 & 1.23 \\
\hline \multirow{3}{*}{$\mathrm{CHOL}(\mathrm{mmol} / \mathrm{l})$} & 1 & $1.42^{\mathrm{I}}$ & 1.10 & 1.83 & $1.38^{\mathrm{I}}$ & 0.99 & 1.93 \\
\hline & 10 & $2.37^{\mathrm{a}, \mathrm{II}}$ & 1.84 & 3.05 & $1.44^{\mathrm{b}, \mathrm{I}}$ & 1.03 & 2.00 \\
\hline & 30 & $3.83^{\text {III }}$ & 2.95 & 4.96 & $3.25^{\mathrm{I}, \mathrm{II}}$ & 2.30 & 4.60 \\
\hline \multirow{3}{*}{ UREA (mmol/1) } & 1 & $4.31^{\mathrm{I}}$ & 3.36 & 5.53 & $4.52^{\mathrm{I}}$ & 3.27 & 6.25 \\
\hline & 10 & $2.52^{\mathrm{II}}$ & 1.96 & 3.23 & $2.21^{\mathrm{II}, 1}$ & 1.61 & 3.07 \\
\hline & 30 & 3.29 & 2.56 & 4.23 & $4.04^{2}$ & 2.86 & 5.70 \\
\hline \multirow{3}{*}{ GGT $(\mu \mathrm{kat} / \mathrm{l})$} & 1 & $0.39^{\mathrm{a}}$ & 0.29 & 0.53 & $0.24^{\mathrm{b}, 1}$ & 0.16 & 0.36 \\
\hline & 10 & 0.42 & 0.31 & 0.57 & $0.49^{2}$ & 0.33 & 0.72 \\
\hline & 30 & 0.46 & 0.33 & 0.63 & $0.53^{2}$ & 0.35 & 0.81 \\
\hline \multirow{3}{*}{$\operatorname{AST}(\mu \mathrm{kat} / \mathrm{l})$} & 1 & $3.02^{\mathrm{I}}$ & 2.16 & 4.24 & 2.07 & 1.32 & 3.26 \\
\hline & 10 & $1.38^{\mathrm{II}}$ & 0.98 & 1.96 & 1.74 & 1.09 & 2.77 \\
\hline & 30 & $1.17^{\text {II }}$ & 0.84 & 1.62 & 1.54 & 1.00 & 2.37 \\
\hline \multirow{3}{*}{$\operatorname{ALP}(\mu \mathrm{kat} / \mathrm{l})$} & 1 & 0.78 & 0.61 & 1.00 & $0.62^{1}$ & 0.46 & 0.84 \\
\hline & 10 & 0.60 & 0.46 & 0.80 & 0.83 & 0.59 & 1.16 \\
\hline & 30 & 0.71 & 0.47 & 1.07 & $1.40^{2}$ & 0.77 & 2.54 \\
\hline \multirow{3}{*}{ HAPT (g/l) } & 1 & $0.69^{\mathrm{I}, 1}$ & 0.52 & 0.91 & $0.62^{1}$ & 0.42 & 0.89 \\
\hline & 10 & $0.33^{\mathrm{a}, \mathrm{II}}$ & 0.25 & 0.43 & $0.50^{\mathrm{b}}$ & 0.35 & 0.70 \\
\hline & 30 & $0.37^{2}$ & 0.28 & 0.48 & $0.33^{2}$ & 0.22 & 0.47 \\
\hline
\end{tabular}

a,b - mean values with different superscripts within the row differ significantly $(P<0.05)$

1,2 - mean values of the indicator with different superscripts within the column differ significantly $(P<0.05)$

I,IIIIII - mean values of the indicator with different superscripts within the column significantly differ $(P<0.01)$

NEFA - non-esterified fatty acids; BHB - beta-hydroxybutyrate; CHOL - cholesterol; UREA - urea; GGT gamma-glutamyl transferase; AST - aspartate aminotransferase; ALP - alkaline phosphatase; HAPT - haptoglobin 
laboratory conditions. Contrary to them, a study by Roy et al. (2008) under field conditions did not find any significant differences in any of the tested parameters.

In conclusion, we showed that although the changes in the biochemical profile related to cows' recovery from LDA were predominant, their dynamics were more favourable for laparoscopic correction of LDA (Janowitz's method) compared to laparotomy (Dirksen's method). It confirms previous laboratory and clinical indices of expediency of LDA laparoscopic treatment under field conditions.

\section{References}

Constable P, Grunberg W, Staufenbiel R, Stampfli HR 2013: Clinicopathologic variables associated with hypokalemia in lactating dairy cows with abomasal displacement or volvulus. J Am Vet Med Assoc 242: 826-835

Delgado-Lecaroz R, Warnick LD, Guard CL, Smith MC, Barry DA 2000: Cross-sectional study of the association of abomasal displacement or volvulus with serum electrolyte and mineral concentrations in dairy cows. Can Vet J 41: 301-305

Dirksen G 1967: Present state of diagnosis, treatment and prophylaxis of left displacement of bovine abomasum (in German). Dtsch Tierärztl Wochenschr 74: 625-633

Illek J, Kumprechtova D, Kudrna V 2011: Metabolic disorders of dairy cows in the peripartum period with respect to changes in body condition. $6^{\text {th }}$ European Congress of Bovine Health Management, 7-9 September 2011, Liege, Belgium 1087 p.

Janowitz H 1998: Laparoscopic reposition and fixation of the left displaced abomasum (in German). Tierärztl Prax 26: 308-313

LeBlanc SJ, Leslie KE, Duffield TF 2005: Metabolic predictors of displaced abomasum in dairy cattle. J Dairy Sci 88: 159-170

Littell RC, Pendergast J, Natarajan R 2000: Modelling covariance structure in the analysis of repeated measures data. Statistics in Medicine 19: 1793-1819

Markusfeld O 1986. The association of displaced abomasums with various periparturient factors in dairy cows. A retrospective study. Prev Vet Med A 19: 172-183

Neves RC, Leno BM, Curler MD, Thomas MJ, Overton, TR, McArt JAA 2018: Association of immediate postpartum plasma calcium concentration with early-lactation clinical diseases, culling, reproduction, and milk production in Holstein cows. J Dairy Sci 101: 547-555

Newman KD 2009: Laparoscopy in large animal surgery. In: Anderson DE, Rings DM (Eds): Food Animal Practice, $5^{\text {th }}$ edn, Elsevier, pp. 406-413

Niehaus AJ 2016: Surgical management of abomasal disease. Vet Clin North Am Food Anim Pract 32: 629-644

Pechova A, Hofirek B, Pavlata L, Dvorak R 2009: Metabolic profile tests (in Czech). In: Hofirek B, Dvorak R, Nemecek L, Dolezel R, Pospisil Z (Eds): Diseases of Cattle (in Czech). $1^{\text {st }}$ edn, Noviko, pp. 1039-1048

Pistkova K, Illek J, Kadek R 2019: Determination of antioxidant indices in dairy cows during the periparturient period. Acta Vet Brno 88: 3-9

Rohn M, Tenhagen B, Tenhagen A, Hofmann W 2004: Survival of dairy cows after surgery to correct abomasal displacement: 2. Association of clinical and laboratory parameters with survival in cows with left abomasal displacement. J Vet Med A Physiol Pathol Clin Med 51: 300-305

Roy JP, Harvey D, Bélanger AM, Buczinski S 2008: Comparison of 2-step laparoscopy-guided abomasopexy versus omentopexy via right flank laparotomy for the treatment of dairy cows with left displacement of the abomasum in on farm setting. J Am Vet Med Assoc 232: 1700-1706

Seeger T, Kumper H, Failing K, Doll K 2006: Comparison of laparoscopic - guided abomasopexy versus omentopexy via right flank laparotomy for the treatment of left abomasal displacement in dairy cows. Am J Vet Res 67: 472-478

Sickinger M 2017: Abomasal displacement in cattle - short overview of recent research results. Tierarztl Prax Ausg Grosstiere Nutztiere 45: 187-190

Simões PB., Campbell AM, Viora L, Gibbons J, Geraghty TE, Eckersall PD, Zadoks RN 2017: Pilot study into milk haptoglobin as an indicator of udder health in heifers after calving. Res Vet Sci 116: 83-87

Staufenbiel R, Ahmed MM, Baumgartner W, Gelfert CC 2007: The use biochemical and hepaticparameters to predict treatment outcome of dairy cows suffering from displacement of the abomasum. Dtsch Tierarztl Wochenschr 114: 225-230

Whitaker DA 2004: Metabolic Profiles. In: Andrews AH, Blowey RW, Boyd H, Eddy RG (Eds): Bovine Medicine: Diseases and Husbandry of Cattle, $2^{\text {nd }}$ edn, Blackwell Publishing Company, Iowa, pp. 804-817

Van Winden SCL, Kuiper R 2003: Left displacement of the abomasums in dairy cattle: recent developments in epidemiological and etiological aspects. Vet Res 34: 47-56

Wittek T, Locher LF, Alkaassem A, Constable PD 2009: Effect of surgical correction of left displaced abomasum by means of omentopexy via right flank laparotomy or two step laparoscopy - guided abomasopexy on postoperative abomasal emptying rate in lactating dairy cows. J Am Vet Med Assoc 234: 652-657 
Wittek T, Fürll M, Grosche A 2012: Peritoneal inflammatory response to surgical correction of left displaced abomasum using different techniques. Vet Rec 171: 594-594 